\title{
A PMR STUDY OF THE ANOMERIC PROTONS IN PERTRIMETHYLSILYL OLIGOSACCHARIDES, A DETERMINATION OF THE CONFIGURATION OF THE GLYCOSIDIC BOND
}

\author{
J. P. Kamerling, M. J. A. De Bie and J. F. G. Vliegenthart \\ Laboratory of Organic Chemistry, University of Utrecht, The Netherlands
}

(Received in the UK 10 January 1972; Accepted for publication 23 February 1972)

\begin{abstract}
The $\delta$-values and coupling constants $J_{1,2}$ of the anomeric protons of 30 pertrimethylsilyl oligosaccharides, obtained from the $100 \mathrm{MHz}$ PMR spectra of these derivatives, are given. Based on these data a method has been developed for the determination of the configuration of the glycosidic bond in oligosaccharides. The influence of substitution of an $\mathrm{OH}$ group by another sugar unit on the chemical shift of the anomeric proton in D-glucose was studied.
\end{abstract}

INTRODUCTION

THE DETERMINATION of the configuration of the glycosidic linkages in free oligosaccharides by means of PMR spectroscopy was introduced by Van der Veen. ${ }^{1}$ The method is based on the observation that in aldohexopyranoses the anomeric protons are shifted more downfield than the nonanomeric ones. The same holds for the protons of the glycosidic linkage, because they are also attached to a $\mathrm{C}$-atom which is linked to two $\mathrm{O}$-atoms. The assignment of the signals is possible if the saccharide units occur in a chair conformation. The anomeric protons in the equatorial position are more deshielded than those in the axial position as a result of a stronger interaction with the p-orbitals of the ring $\mathrm{O}$-atom. The chemical shift is also influenced by the electric fields and magnetic anisotropies associated with the $\mathrm{C}_{2}-\mathrm{C}_{3}, \mathrm{C}_{5}-\mathrm{O}_{5}$ and $\mathrm{O}_{1}-\mathrm{X}$ bonds ( $\mathrm{X}=$ substituent). Axial-axial coupling between the protons on $\mathrm{C}_{1}$ and $C_{2}$ results in a coupling constant $J_{1,2}$ of $6-8 \mathrm{~Hz}$, whereas equatorial-equatorial, equatorial-axial or axial-equatorial coupling gives a $J_{1,2}$ value of $1-4 \mathrm{~Hz}$.

In a preliminary communication ${ }^{2}$ we discussed the applicability of pertrimethylsilyl derivatives for the determination of the configuration of the glycosidic bonds. Hellerqvist $e t$ al. ${ }^{3}$ extended these data and included also the corresponding alditols in their study. Whyte described the use of permethyl derivatives ${ }^{4}$ and of free alditols. ${ }^{5}$ By reduction of the saccharides to alditols the spectrum becomes simpler because the resonances of the anomeric protons of the reducing unit are eliminated. In all these investigations the oligosaccharides were built up from D-glucose, D-galactose, Dmannose and/or D-fructose. For the interpretation of the results it was supposed that the aldohexoses occur in the $\mathrm{Cl}$ (D) conformation. This assumption is also justified for pertrimethylsilyl derivatives (Streefkerk et al. ${ }^{6}$ ).

Here we give a survey of the pertrimethylsilyl (TMS) oligosaccharides investigated by us and discuss the scope of this PMR method. 


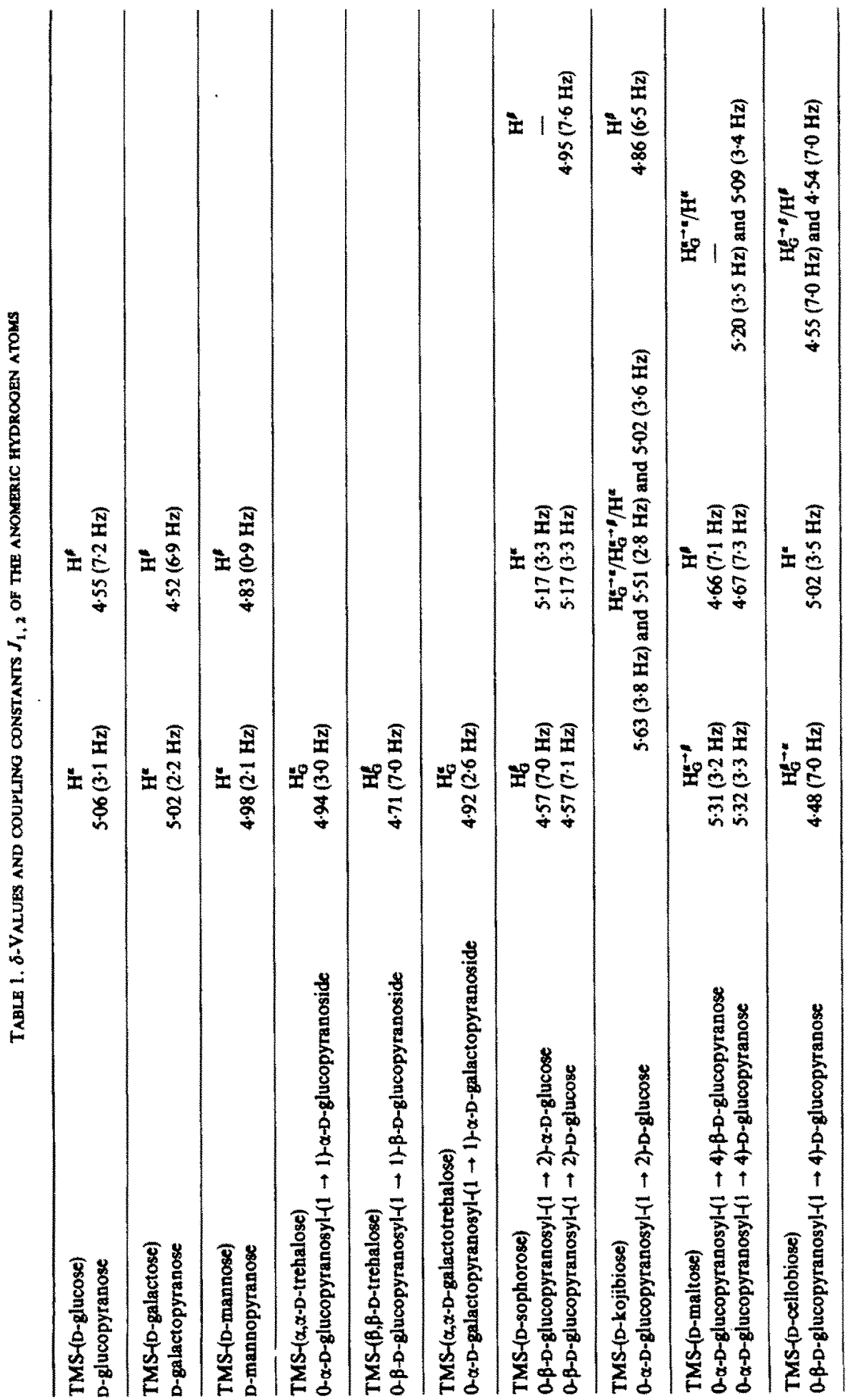




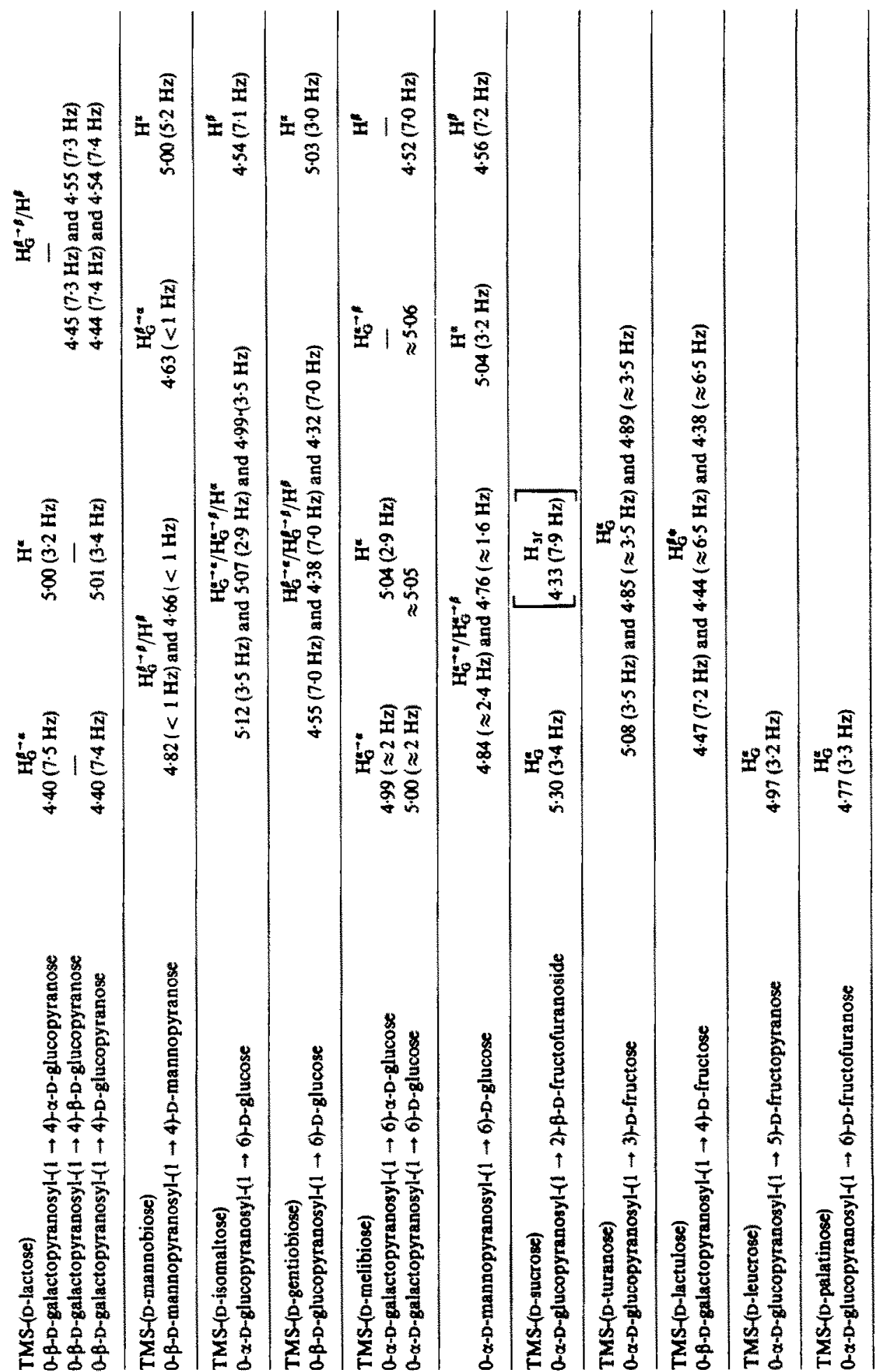




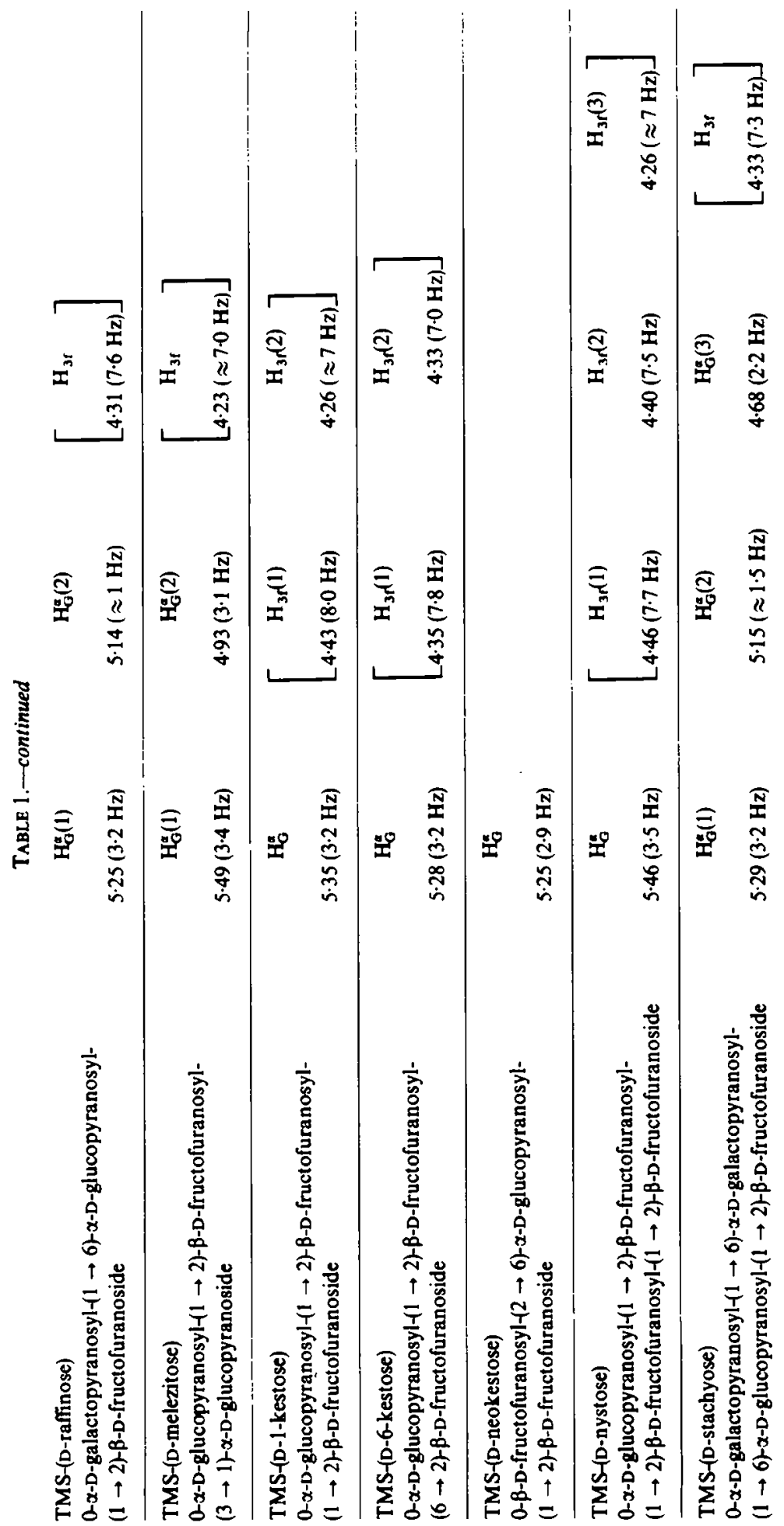




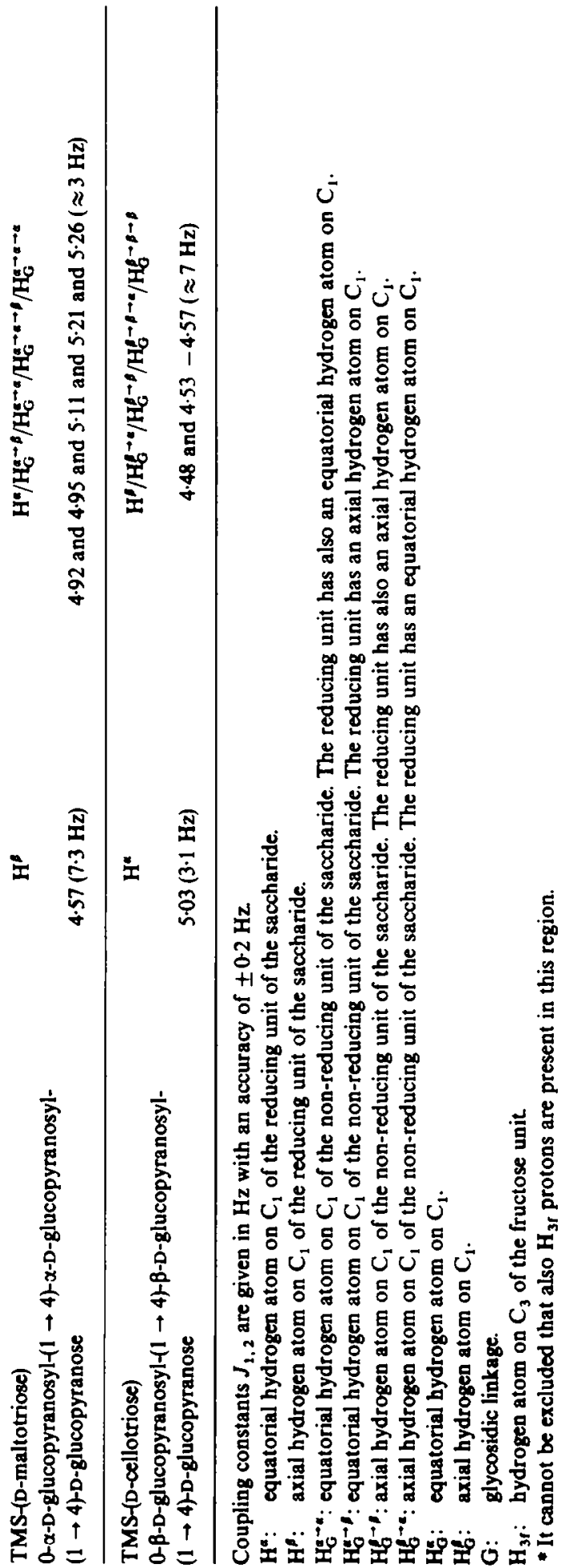




\section{RESULTS}

Each of the PMR spectra of the TMS-derivatives of the aldosyl oligosaccharides can be divided roughly into three groups of signals: i. The $\mathrm{OSi}\left(\mathrm{CH}_{3}\right)_{3}$ groups give sharp and strong singlets between $\delta=0.0-0.3 \mathrm{ppm}$, ii. The non-anomeric protons resonate between $\delta=2.9-4.3 \mathrm{ppm}$, iii. The anomeric protons resonate between $\delta=4.3-5.7 \mathrm{ppm}$ (the TMS-sugars were dissolved in aceton- $d_{6}$ ). The axial anomeric protons are observed between $\delta=4 \cdot 3-5.0 \mathrm{ppm}$ and the equatorial anomeric protons between $\delta=4 \cdot 7-5 \cdot 7 \mathrm{ppm}$. The PMR spectra of the TMS-derivatives of the oligosaccharides containing one or more fructose units can be divided into three ranges in the same way. However, the non-anomeric protons resonate between $\delta=3.0-4.5$ $\mathrm{ppm}$. In Table 1 the $\delta$-values and the coupling constants $J_{1,2}$ of the anomeric protons of 30 TMS-oligosaccharides are summarized.

\section{Determination of the configuration of the glycosidic linkage}

On the basis of differences in the coupling constants $J_{1,2}$ a method for the determination of the configuration of the glycosidic bond can be developed. ${ }^{1,2}$ For the assignment of the anomeric proton signals the monosaccharide sequence must be known as well as whether the oligosaccharide is reducing or non-reducing.

For the non-reducing symmetrical disaccharides IV, V and VI (Table) the configuration of each glycosidic linkage can be easily established (Fig: 1). The doublets of each hydrogen atom on the anomeric $\mathrm{C}_{1}$-atoms of the glycosidic link have the same chemical shift.

The PMR spectra of the reducing TMS-aldosyl oligosaccharides are built up from the spectra of the actually present anomeric forms. The anomeric region in the PMR spectrum of TMS-D-lactose (XI) is composed of the signals of the anomeric protons in the spectra of TMS- $\alpha$-D-lactose $[\delta=4.40(7.5 \mathrm{~Hz})$ and $\delta=5.00(3.2 \mathrm{~Hz})]$ and TMS- $\beta$-D-lactose $[\delta=4.45(7.3 \mathrm{~Hz})$ and $4.55(7.3 \mathrm{~Hz})]$ respectively. The presence of three signals with a large coupling constant of about $7 \mathrm{~Hz}$ and one signal with a coupling constant of about $3 \mathrm{~Hz}$ in TMS-D-lactose points to a $\beta$ configuration for the glycosidic link. The spectrum of TMS-D-maltose (IX) (Fig. 2) shows three anomeric signals with a coupling constant of about $3 \mathrm{~Hz}$ (axial-equatorial coupling) and one anomeric signal with a coupling constant of about $7 \mathrm{~Hz}$ (axial-axial coupling). Therefore the configuration of the glycosidic link must be $\alpha$ (equatorial orientation). In a similar way all recorded spectra were interpreted. In the case of TMS-D-sophorose (VII) the signals of $\mathrm{H}_{G}^{\beta \rightarrow \alpha}$ and $\mathrm{H}_{G}^{\beta \rightarrow \beta}$ coincide $\left[\mathrm{H}_{G}^{\beta}: \delta=4.57(7.0 \mathrm{~Hz})\right]$. However, taking into account the intensities of the anomeric signals the configuration of the glycosidic link can be unequivocally established (intensity $\mathrm{H}^{\alpha}+$ intensity $\mathrm{H}^{\beta}=$ intensity $\mathrm{H}_{G}^{\beta}$ ). The coupling constants $J_{1,2}$ of $\alpha$ - and $\beta$-D-mannose are very similar. Therefore a configuration determination in mannosyl-aldohexoses is difficult.

Proton chemical shifts are generally solvent dependent. In our investigations we used aceton- $d_{6}$. When the spectrum was too difficult to interprete also $\mathrm{CCl}_{4}, \mathrm{C}_{6} \mathrm{D}_{6}$ and $\mathrm{CDCl}_{3}$ were applied. The PMR spectrum of TMS-D-melibiose (XV) recorded in aceton- $d_{6}$ shows a complicated pattern of anomeric protons, but in $\mathrm{C}_{6} \mathrm{D}_{6}$ four separated doublets are visible in this region. In aceton $-d_{6} \mathrm{H}_{G}^{\alpha \rightarrow \beta}$ and $\mathrm{H}^{\alpha}$ coincide nearly.

The PMR spectrum of TMS-D-turanose (XVIII) shows three signals with a small coupling constant; evidently the configuration must be $\alpha$ It is known that all five anomeric forms of glucosyl- $\alpha(1 \rightarrow 3)$-fructose exist in water i.e. two pyranose, two 


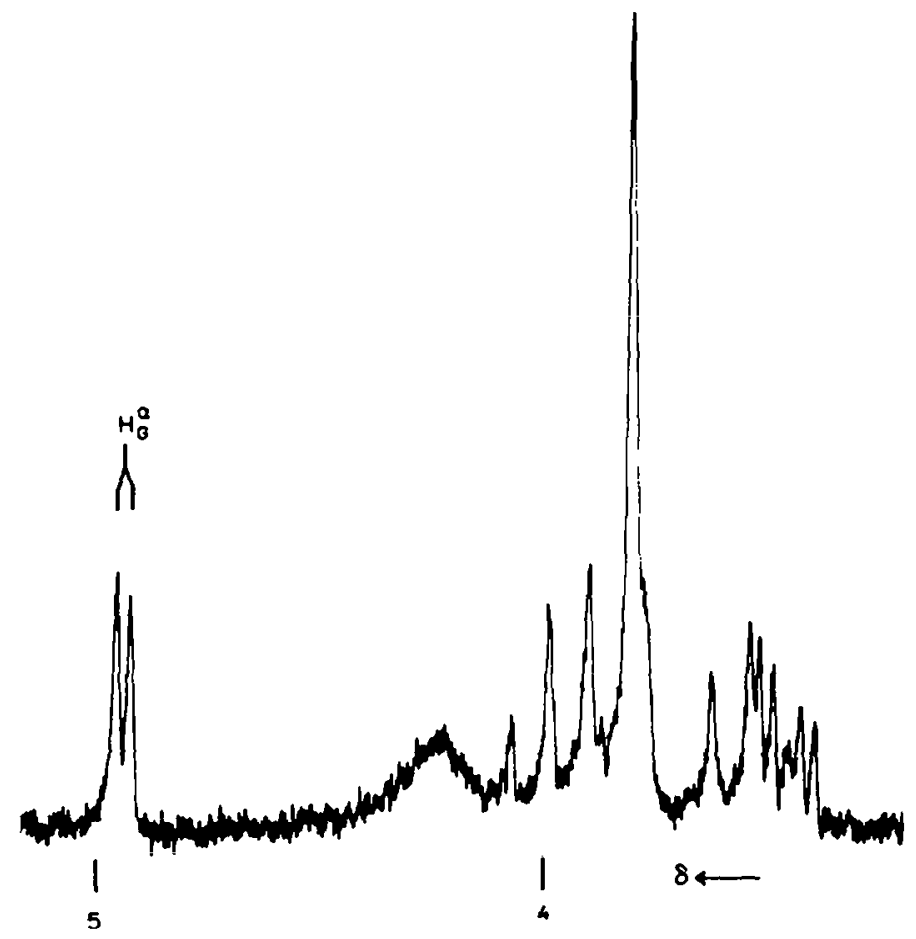

FIG 1. PMR spectrum at $100 \mathrm{MHz}$ in aceton- $d_{\sigma}$ of TMS- $x, x-\mathrm{D}$-trehalose. The signals of the trimethylsilyl groups are not given.
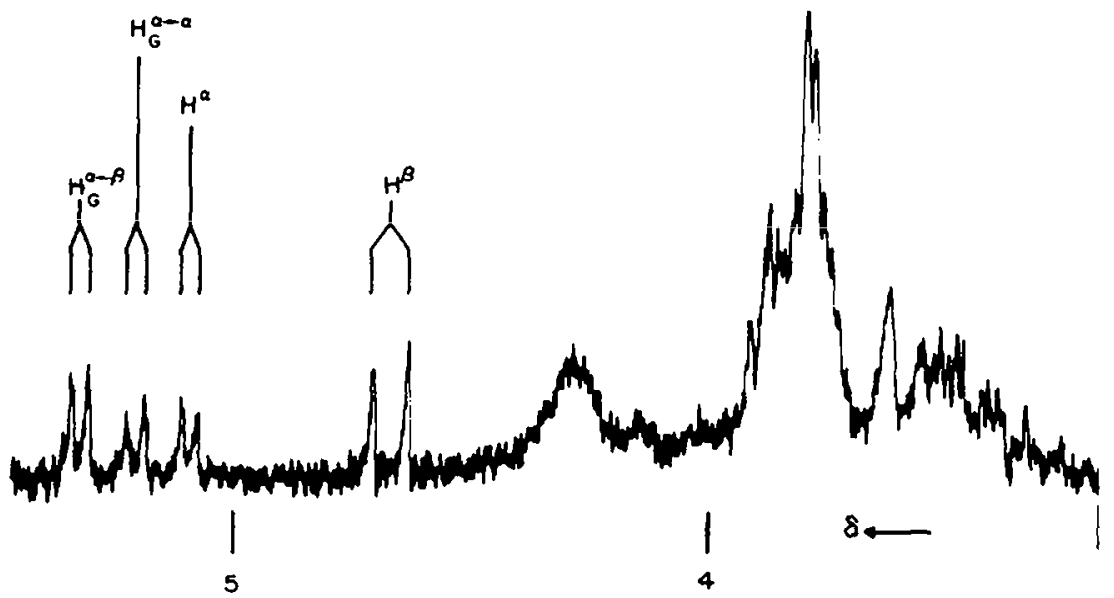

Fig 2. PMR spectrum at $100 \mathrm{MHz}$ in aceton- $d_{6}$ of TMS-D-maltose. The signals of the trimethylsilyl groups are not given.

The broad peak at $\delta \approx 4.3$ is an artefact sometimes present as a result of the silylation procedure. 
furanose and one acyclic form of fructose. ${ }^{7,8}$ Doddrell et al. have shown by ${ }^{13} \mathrm{C}$ NMR spectroscopy that in $1 \mathrm{M}$ turanose solution in $\mathrm{H}_{2} \mathrm{O}$ at $\mathrm{pH}=5$ and $36^{\circ} 39 \pm 4 \%$ $\beta$-pyranose, $20 \pm 2 \% \alpha$-furanose and $41 \pm 4 \% \beta$-furanose are present. The other two forms occur in amounts of less than $5 \%$, and could not be detected. Our experimental results support these percentages. In the spectrum of TMS-D-lactulose (XIX) more than one doublet with a coupling constant of about $7 \mathrm{~Hz}$ is present. In this case too five anomeric forms can be expected. Because there is no sharp separation between the anomeric and the non-anomeric $\delta$-range, it is difficult to give a decisive answer concerning the number of anomers present.

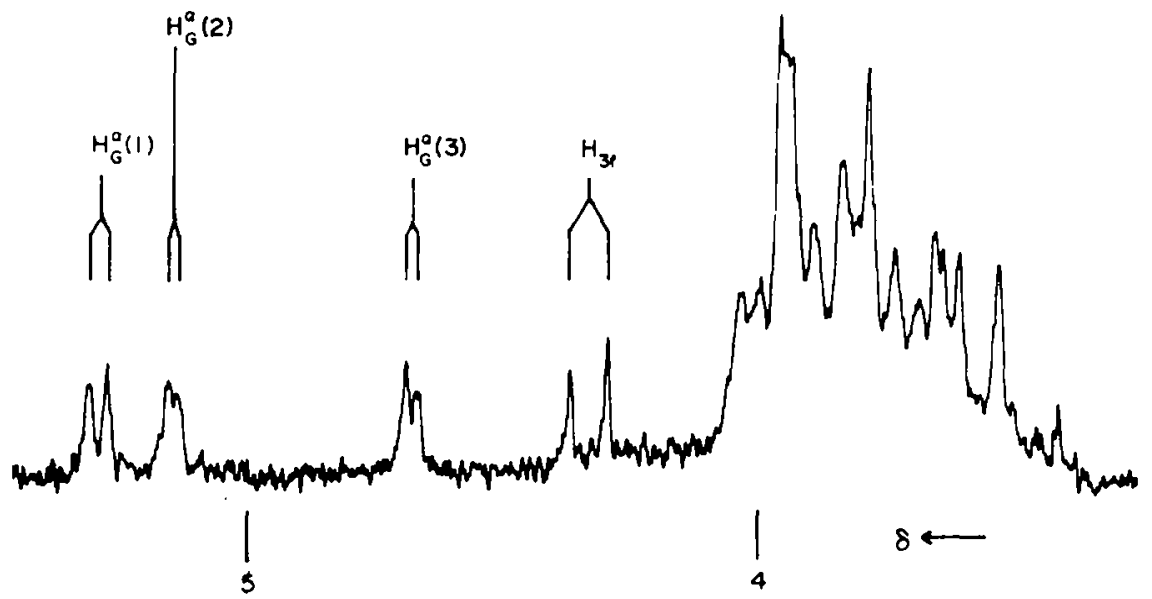

FIG 3. PMR spectrum at $100 \mathrm{MHz}$ in aceton- $d_{6}$ of TMS-D-stachyose. The signals of the trimethylsilyl groups are not given.

In the fructosyl-oligosaccharides the resonance of $\mathrm{H}_{3}$ of the fructose appears sometimes as a doublet with a large coupling constant, separated from the other nonanomeric protons. A typical example is the PMR spectrum of TMS-stachyose (XXVIII) (Fig. 3). Taking into account that in this tetrasaccharide a fructofuranose unit is present, the configuration of all three glycosidic links must be $\alpha$ (equatorial orientation).

In some special cases the monosaccharide sequence can be confirmed by the PMR spectrum. For instance, in the spectrum of TMS- $\alpha-D-M a n p-(1 \rightarrow 6)-D-G$ (XVI) one doublet with a $J_{1,2}$ value of about $7 \mathrm{~Hz}$ and three doublets with $J_{1,2}$ values of $2-3 \mathrm{~Hz}$ were observed (Table). The PMR spectra of TMS- $\alpha$ - and $\beta$-D-mannose show $J_{1,2}$ values of $2.1 \mathrm{~Hz}$ and $0.9 \mathrm{~Hz}$ respectively, while in the spectra of TMS- $\alpha-$ and $\beta-D-$ glucose coupling constants $J_{1,2}$ of $3 \cdot 1 \mathrm{~Hz}$ and $7 \cdot 2 \mathrm{~Hz}$ were observed respectively. Because in the spectrum of XVI only one of the four doublets has a coupling constant of about $7 \mathrm{~Hz}$, the sequence must be mannose-glucose.

Influence of substitution of an $\mathrm{OH}$ group by another sugar unit on the chemical shift of $\mathrm{H}_{1}$ in D-glucose

Comparison of the chemical shifts of $\mathrm{H}^{\alpha}$ in oligosaccharides, containing glucose as reducing unit, with that of the same proton in TMS- $\alpha$-D-glucopyranose (I) $(\delta=5.06$ 
ppm; $J_{1,2}=3 \cdot 1 \mathrm{~Hz}$ ) shows that substitution at $\mathrm{C}_{4}$ or $\mathrm{C}_{6}$ causes only minor differences. For the saccharides X, XI, XIV, XV, XVI and XXX the shift of $\mathrm{H}^{x}$ varies from 5.00-5.06 ppm (Table). Therefore it is reasonable to assume that in TMS-D-maltose (IX) the proton resonating at $\delta=5.09 \mathrm{ppm}$ is $\mathrm{H}^{\alpha}$. Substitution at $\mathrm{C}_{2}$ shows in the case of TMS-D-sophorose (VII) a greater deviation for $\mathrm{H}^{\alpha}$, because the chemical shift is $5.17 \mathrm{ppm}$. Taking all these data into account, the chemical shift of $\delta=5.02 \mathrm{ppm}$, observed in the other $\mathrm{C}_{2}$-example TMS-kojibiose (VIII) must be due to $\mathrm{H}^{\mathrm{a}}$. Comparison of the data of $\mathrm{H}^{\beta}$ in oligosaccharides, containing glucose as reducing unit with $\mathrm{H}^{\beta}$ of TMS- $\beta$-D-glucopyranose, which has a $\delta$-value of $4.55 \mathrm{ppm}\left(J_{1,2}=7.2 \mathrm{~Hz}\right)$, demonstrates that substitution at $\mathrm{C}_{4}$ or $\mathrm{C}_{6}$ has a smaller effect on the chemical shift of $\mathrm{H}^{\beta}$ than substitution at $C_{2}$. For the $1 \rightarrow 4$ and $1 \rightarrow 6$ saccharides IX, X, XIII, XV, XVI and XXIX the chemical shift varies between $\delta=4.52-4.67 \mathrm{ppm}$, while for the $1 \rightarrow 2$ disaccharides VII and VIII values of $4.95 \mathrm{ppm}$ and $4.86 \mathrm{ppm}$ were found respectively. Probably the signals at $\delta=4.54$ in XI $(1 \rightarrow 4)$ and $\delta=4.55$ in XIV $(1 \rightarrow 6)$ arise from $\mathbf{H}^{p}$.

Substitution on $C_{1}$ causes very divergent chemical shifts for $H^{\alpha}\left(=H_{G}^{\alpha}, H_{G}^{a \rightarrow \beta}\right.$ or $\mathrm{H}_{\mathrm{G}}^{\alpha \rightarrow \infty}$ ) with regard to the $\delta$-value for this proton in TMS- $\alpha$-D-glucopyranose. The extremes are TMS-D-kojibiose $\left(\mathrm{H}_{\mathrm{G}}^{\alpha \rightarrow \beta} / \mathrm{H}_{\mathrm{G}}^{\alpha \rightarrow \alpha}: \delta=5.63\right.$ and $\left.5.51 \mathrm{ppm}\right)$ and TMS-Dpalatinose $\left(\mathrm{H}_{\mathrm{G}}^{\alpha}: \delta=4.77 \mathrm{ppm}\right)$. For $\mathrm{H}^{\beta}\left(=\mathrm{H}_{\mathrm{G}}^{\beta}, \mathrm{H}_{\mathrm{G}}^{\beta \rightarrow \alpha}\right.$ or $\left.\mathrm{H}_{\mathrm{G}}^{\beta \rightarrow \beta}\right)$ the extremes are TMS- $\beta, \beta-D-t r e h a l o s e\left(H_{a}^{\beta}: \delta=4.71 \mathrm{ppm}\right)$ and TMS-D-gentiobiose $\left(\mathrm{H}_{\mathrm{G}}^{\beta \rightarrow \alpha} / \mathrm{H}_{\mathrm{G}}^{\beta \rightarrow \beta}\right.$ : $\delta=4.32$ and $4.38 \mathrm{ppm}$ ), whereas the $\delta$-value for this proton in TMS- $\beta$-D-glucopyranose is $4.55 \mathrm{ppm}$.

From these comparisons we may conclude that in $1 \rightarrow 2$ glucosyl-glucoses the $\beta$ configuration of the proton on $C_{1}$ of the reducing end (axial orientation) is more influenced by this type of glycosidic link than the $\alpha$-configuration (equatorial orientation). Furthermore, the anomeric proton on $C_{1}$ of the non-reducing unit in $\alpha$-position $[\alpha(1 \rightarrow x)$ linkage $]$ is more influenced by $x$ and by the reducing unit than in $\beta$-position $[\beta(1 \rightarrow x)$ linkage $]$.

\section{DISCUSSION}

The general advantage of the analysis of derivatives over free saccharides is that in the spectra of the derivatives the more or less broad HOD signal, which is observed in the underivatized compounds (dissolved in $\mathrm{D}_{2} \mathrm{O}$; Van der Veen ${ }^{1}$ ), is eliminated. For several reasons the employment of TMS-derivatives instead of Me- or Acderivatives was preferred. The PMR spectra of the Me-derivatives can be used for the determination of the glycosidic link configuration in a similar way as described for the TMS-derivatives. However, they have the disadvantage that the OMe signals are superimposed on the non-anomeric $\mathrm{CH}$ signals (Whyte ${ }^{4}$ and Casu et al. ${ }^{9}$ ), which hampers the assignment of these last signals. Permethylation with $\mathrm{CD}_{3} \mathrm{I}$ instead of MeI eliminates this problem, but eliminates also a lot of information which could be derived from the OMe signals. The use of peracetyl derivatives is not advisable for configurational determinations of the glycosidic links in oligosaccharides. The great deshielding effect of the Ac group causes the signal of the anomeric proton on $\mathrm{C}_{1}$ of the glycosidic link to fall within the range of the non-anomeric ones (Binkley et al., ${ }^{10}$ Casu et al., ${ }^{11}$ Friebolin et al. ${ }^{12,13}$ ). However, in comparison with the TMS ethers, the non-anomeric protons are spread over a larger $\delta$-range, which can be of importance for the assignment of these signals (Ac: about $2 \mathrm{ppm}$; TMS: $1-1.5 \mathrm{ppm}$ ). Compared 
with the permethylation and peracetylation, the pertimethylsilylation is a simple procedure, which results in the case of reducing sugars in a mixture of TMS-anomeric forms, having nearly the same composition as in the starting medium e.g. $\mathrm{H}_{2} \mathrm{O}$ (Sweeley et al..$^{14}$ and Shallenberger $e t a l . .^{15}$ this study). PMR spectroscopy of TMSderivatives can also be used for the determination of the position of the anomeric equilibrium, provided that the quantity of each present anomer is more than $5 \%$. Because of their high volatility, TMS-derivatives are also widely applied in gas-liquid chromatography and mass spectrometry. It is obvious that a great amount of information can be obtained by using the TMS ethers. However, for a number of special cases the other derivatives have to be preferred (e.g. the assignment of the methylene bridges in Ac-oligosaccharides related to sucrose; Binkley et al. ${ }^{10}$ and Arcamone et al. ${ }^{16}$ ).

The presented method offers the possibility of the determination of the configuration of the glycosidic linkage in oligosaccharides which contain monosaccharides with an axial proton on $\mathrm{C}_{2}$ (e.g. D-glucose and D-galactose). Oligosaccharides which contain a monosaccharide with an equatorial proton on $\mathrm{C}_{2}$ as non-reducing unit give rise to difficulties (e.g. D-mannose), because of the little difference between an equatoriat equatorial and an axial-equatorial coupling. The presence of D-mannose can also lead to other problems. In the PMR spectrum of TMS- $\beta$-D-Manp-( $1 \rightarrow 4)-\alpha-D-M a n p$ the anomeric proton of the reducing mannose unit resonates at $\delta=5.00 \mathrm{ppm}$ and has a coupling constant $J_{1,2}$ of $5.2 \mathrm{~Hz}$. This value is intermediate between an equatorial-equatorial and an axial-axial coupling. It may be that in TMS-D-mannobiose exists an equilibrium between the $\mathrm{Cl}(\mathrm{D})$ and $\mathrm{CC}(\mathrm{D})$ conformation with regard to the reducing mannose unit. Onodera ${ }^{17}$ has described this phenomenon for certain derivatives of $\alpha$-D-mannose, e.g. 9-( $\alpha$-D-mannopyranosyl)-adenine hydrochloride. The mannobiose problem is still under investigation.

Recently, Hellerqvist et $a l^{3}$ have suggested to look for the TMS-alditols of the reducing oligosaccharides, because of the reduction of the number of anomeric signals. For disaccharides this step is not necessary. By $\mathrm{NaBH}_{4}$ reduction a lot of information about the reducing sugar unit e.g. concerning the ring size is eliminated. The coupling constants of the anomeric protons on $\mathrm{C}_{1}$ of a furanose ring are different from those of a pyranose ring (Acree et al. ${ }^{18}$ ). However, the complexity of the spectra of the reducing higher oligosaccharides makes a conversion to the corresponding alditols advisable.

The three kestoses, frequently found in Nature, can be distinguished on the basis of the PMR spectra of their TMS ethers. Even the anomeric signals show different chemical shifts. Together with the mass spectrometrical characterization of their TMS derivatives, ${ }^{19}$ the PMR technique forms a valuable addition of the methods used up to now for differentiation between the three kestoses.

Some preliminary experiments have shown that by using the Fourier Transform technique, it is possible to study very small amounts of carbohydrate materials (1 $\mu \mathrm{mol})$. For this reason the method can be very helpful in the structural elucidation of oligosaccharides and of the carbohydrate part of glycolipids and glycoproteins.

\section{EX PERIMENTAL}

The trimethylsilyl derivatives were prepared as follows: $10 \mathrm{mg}$ of an oligosaccharide was dissolved in $1 \mathrm{ml}$ pyridine. Subsequently $0.4 \mathrm{ml}$ hexamethyldisilazane and $0.2 \mathrm{ml}$ trimethylchlorosilane were added. After two $\mathrm{hr}$ at room temperature for disaccharides or $3 \mathrm{hr}$ at $60^{\circ}$ for higher oligosaccharides $3 \mathrm{ml}$ hexane 
and $3 \mathrm{ml}$ water were added to the turbid mixture. The two layer system was strongly agitated and the water layer removed. The hexane layer was washed with $1 \mathrm{ml} \mathrm{H}_{2} \mathrm{O}$, dried $\left(\mathrm{Na}_{2} \mathrm{SO}_{4}\right)$ and evaporated in vacuo. The residue was dissolved in $0.5 \mathrm{ml}$ aceton- ${ }_{6}$. If the oligosaccharide did not dissolve easily in pyridine, a small drop of water was added before the addition of pyridine. In this case $0.8 \mathrm{ml}$ HMDS and $0-4 \mathrm{ml}$ TMCS were used. Reducing oligosaccharides were anomerized in water during $48 \mathrm{hr}$ at room temperature. Silylation of disaccharides containing a fructose unit with a free hemiacetal hydroxy group is very difficult. To obtain a complete (more than $99 \%$ silylation, it is necessary to react for $48 \mathrm{hr}$ at $60^{\circ}$.

The carbohydrates were obtained from J. T. Baker Chemicals N.V., Pierce Chemicals Company or EGA-Chemie K.G. or were gifts made available by several investigators (see acknowledgements).

The PMR spectra were recorded with a Varian HA 100 spectrometer, locked on the trimethylsilyl peaks, or a Varian XL 100 spectrometer, locked on deuterium of the solvent aceton- $d_{6}$. The chemical shifts are given relative to tetramethylsilane in the $\delta$-scale (indirect to aceton- $d_{f} ; \delta=2.05 \mathrm{ppm}$ ) at room temperature.

Acknowledgements-For valuable gifts of samples we are indebted to Prof. Dr. G. O. Aspinall (mannobiose), Dr. J. S. C. Bacon (1-kestose and neokestose), Dr. G. G. Birch ( $\beta, \beta$-trehalose and $\alpha, \alpha$-galactotrehalose). Dr. P. A. J. Gorin ( $\alpha$-D-Manp-(1 $\rightarrow$ 6)-D-G), Dr. B. H. Koeppen (sophorose and kojibiose), Prof. Dr. W. Kahl (1-kestose and nystose), Dr. A. J. Michell (cellotriose), Dr. F. H. Stodola (leucrose) and Dr. M. Trojna (6-kestose and neokestose). We thank Miss L. Veldstra (Organic Chemical Institute T.N.O., Utrecht) and Mr. D. Seykens for recording the $100 \mathrm{MHz}$ spectra. This investigation was supported by the Netherlands Foundation for Chemical Research (SON) with financial aid from the Netherlands Organization for the Advancement of Pure Research (ZWO).

\section{REFERENCES}

1 J. M. Van der Veen, J. Org. Chem. 28, 564 (1963)

2 J. P. Kamerling, D. Rosenberg and J. F. G. Vliegenthart, Biochem. Biophys. Res. Comm. 38, 794 (1970)

3 C. G. Hellerqvist, O. Larm and B. Lindberg, Acta Chem. Scand. 25, 743 (1971)

4 J. N. C. Whyte, Carbohyd. Res. 16, 220 (1971)

5 J. N. C. Whyte, Anal. Biochem. 42, 476 (1971)

6 D. G. Streefkerk, M. J. A. de Bie and J. F. G. Vliegenthart, (to be published)

'D. Doddrell and A. Allerhand, J. Am. Chem. Soc. 93, 2779 (1971)

8 G. Avigad, S. Englard and 1. Listowsky, Carbohyd. Res. 14, 365 (1970)

9 B. Casu, M. Reggiani, G. G. Gallo and A. Vigevani, Tetrahedron 24, 803 (1968)

10 W. W. Binkley, D. Horton and N. S. Bhacca, Carbohyd. Res. 10, 245 (1969)

11 B. Casu, M. Reggiani, G. G. Gallo and A. Vigevani, Ibid. 12, 157 (1970)

12 H. Friebolin, G. Koilich and E. Siefert, Org. Magn. Res. 2, 457 (1970)

${ }_{13}$ G. Keilich, E. Siefert and H. Friebolin, Ibid. 3, 31 (1971)

14 C. C. Sweeley, R. Bentley, M. Makita and W. W. Wells, J. Am. Chem. Soc. 85, 2479 (1963)

15 C. Y. Lee, T. E. Acree and R. S. Shallenberger, Carbohyd. Res. 9, 356 (1969)

16 F. Arcamone, W. Barbieri, G. Cassinelli and C. Pol, Ibid. 14, 65 (1970)

17 K. Onodera, Conformational Analysis, vol. 21; Academic Press (1971)

18 T. E. Acree, R. S. Shallenberger and L. R. Mattick, Carbohyd. Res. 6, 498 (1968)

19 J. P. Kamerling, J. F. G. Vliegenthart, J. Vink and J. J. de Ridder, Tetrahedron Letters 2367 (1971) 